CDD: 100

\title{
A PUZZLE FOR PHILOSOPHERS
}

\author{
NICOLÁS LO GUERCIO
}

Instituto de Filosofía

Universidad de Buenos Aires

642 Bulnes st

C1176 ABL BUENOS AIRES

ARGENTINA

nicolasloguercio@gmail.com

Received: 02.01.2013; Revised: 24.07.2013; Accepted: 25.08.2013

\begin{abstract}
In the paper I tackle a puzzle by Goldberg (2009) that challenges all of us as philosophers. There are three plausible thesis, separately defensible, that together seem to lead to a contradiction: 1) Reliability is a necessary condition for epistemic justification. 2) On contested matters in philosophy, philosophers are not reliable. 3) At least some philosophical theses regarding contested matters in philosophy are epistemically justified. In this paper I will assess the status of the puzzle and attempt to solve it. In the first section, I'll present the puzzle with a little more detail. Secondly, I'll provide some general arguments to show that the alleged puzzle is not a legitimate one. Finally, in section 3, I will argue that even assuming that the puzzle can be coherently formulated, Goldberg's arguments in favor of premise (2) are either unsound or too limited in their scope in order to represent a significant or interesting problem for philosophers.
\end{abstract}

Keywords: Justification. Reliability. Philosophical disagreement.

\section{THE PUZZLE}

Here is the puzzle (Goldberg 2009): 1) Reliability is a necessary condition for epistemic justification. 2) On contested matters in philosophy, philosophers are not reliable. 3) At least some philosophical theses regarding contested matters in philosophy are epistemically justified. The three of these statements cannot be simultaneously true, for (1) and (2), together, imply the negation of (3). On the other hand, each of them is independently defensible. Let me summarize very briefly the reasons available for each point. 
(1) It seems that in order to be really epistemic, epistemic justification has to be somewhat connected to truth. Arguably, epistemic justification aims at truth, in the sense that an agent cannot be justified if she forms beliefs through a process that leads to falsity more often than to truth. I'll come back to this point bellow (\$2).

(2) Since I'll be concerned with the arguments in favor of (2) in $\$ 3$, I won't enter into the details here. Let me just advance what I take to be the main idea: arguably, in contested philosophical matters the diversity of opinions is sufficient to conclude either that a) the philosophical method is not a reliable one or b) the philosophical method is reliable but diversity provides an undercutting defeater that precludes justification.

(3) We want to say, as philosophers, that at least some philosophical theses are epistemically justified. And there is some intuitive support for believing this. Take David Lewis as an example. He was a very intelligent philosopher; he was sufficiently clever, reflexive, free from bias, careful in its investigation; he made very serious research regarding some of the main problems in philosophy and he was familiar with all, or almost all, of the pro and contra arguments available; he thought very carefully about those issues, critically examined his own positions and received criticisms from the most respected philosophical peers through a lot of years. As a result, he arrived at some corpus of philosophical beliefs. It seems, prima facie, that he was epistemically justified in believing as he did (If he was not, what's left for the rest of us!).

Before we tackle the problem in the next sections, there is a worry it is necessary to take care of. As it has been suggested by an anonymous referee, one might argue that Goldberg's puzzle doesn't even get off the ground. According to this worry, the puzzle equivocates between two different uses of the term 'justification' in 
premise (1) and (3). As the referee points out, there is at least two different notions of epistemic justification that have been defended in the philosophical literature:

(a) One is justified only if one is blameless for believing as one does.

(b) One is justified only if one's belief amounts to knowledge, if true.

According to the objection, premise (1) makes sense only if understood in line with (b), while premise (3) should be denied unless it is understood in line with (a). If this is right, it seems that we don't have to bother in trying to solve the problem, for there isn't even a problem to start with.

It is worth noting that Goldberg himself is sensitive to this point. In considering the reasons for premise (3) he writes:

The foregoing considerations might fail to convince. After all, nowhere in the preceding paragraph did I make a case for the reliability of my philosophical beliefs. Granted. But consider the cost that must be borne by anyone who denies that at least some of my philosophical beliefs are justified. In that case one must hold that a subject who is normally functioning, reasonably intelligent, hard-working, careful, suitably educated and experienced, who has access to and avails himself of the relevant evidence, and who gives careful consideration of relevant considerations to the contrary, nevertheless systematically fails to arrive at justified belief in the domain in question. This, I submit, is a curious result: where justified belief is possible, we might be forgiven for thinking that it is just such a person who will attain it. What sort of shady activity is philosophy anyway, that it attracts reasonably intelligent people into spending their intellectual lives toiling away, only to be systematically thwarted in their efforts at justified belief? (We don't need an evil demon; philosophy itself is the culprit.) (Goldberg 2009, p. 111)

Admittedly, then, Goldberg does not present positive reasons for reading premise (3) in line with (b). But, as I read it, in the quoted passage he is making the case that being unable to interpret premise (3) 
in line with (b) comes at a high price: we are left with a perplexity, that is, that a normally-function, intelligent and careful individual, with access to all the relevant evidence, would not have knowledge, even if her belief happens to be true. So you might read (3) in line with (a), but that is not less problematic. To be sure, denying that philosophers possess, regarding contested philosophical matters, the kind of justification that turns true beliefs into knowledge amounts to a relevantly strong form of philosophical skepticism, provided that there is widespread disagreement about almost all important philosophical topics (that is, disagreement is almost ubiquitous in philosophy). Philosophical skepticism is something we would like to avoid if possible. So dismissing the problem by invoking an equivocation in the uses of the term 'justification' is one option, but it's not unproblematic at all.

Now, even if one buys that premise (3) cannot be plausibly understood in terms of (b), I'll argue, the puzzle is still pressing. Of course, I ultimately agree with the referee in that Goldberg's puzzle is only apparently problematic. I contend, however, that it is a puzzle worth considering, for premises (1) and (2) provide prima facie reasons for believing that philosophers are not epistemically justified, even in sense (a), when it comes to philosophical contested matters.

Any philosopher that accepts (1) and (2) cannot say that she is epistemically justified, even in sense (a), about some particular contested philosophical matter. If you accept that reliability is a necessary condition for epistemic justification and you are aware that your belief concerns a contested philosophical matter (and proviso the truth of (2), that is, that your belief concerning that matter was not reliably formed), then it seems that you are to blame for believing as you do. Being aware of (1) and (2) seems to preclude epistemic justification, even in the sense of (a), about contested philosophical matters. So, were a philosopher to accept (1) and (2), she would be blameworthy if she holds her belief in the face of controversy. Again, given that 
controversy is ubiquitous within philosophy, this is a worrying consequence.

Another reason for maintaining that the puzzle is compelling even in light of the previous considerations to the contrary can be found in Goldberg's paper. As we'll see in detail in section \$3, Goldberg provides an argument (The Undercutting Defeater Argument) that attempts to show that the fact of widespread disagreement about some philosophical matter provides an undercutting defeater that precludes justification, even if one's belief was reliably formed. So, according to Goldberg, even if we grant that a philosopher is reliable in forming philosophical beliefs about contested philosophical matters, in the face of controversy she is to be epistemically blamed for believing as she does, for she is ignoring the undercutting defeater provided by the fact of disagreement. This is a consequence sufficiently uneasy to hold, for one would want to say that, at least in some cases, one has justification in sense (a) even in the face of controversy.

So, I believe there are reasons to maintain that the puzzle is prima facie worrying. In the next two sections I will attempt to provide a solution to these problems. In section ( $(2)$, I'll argue that there are some general worries that cast doubts concerning the legitimacy of the puzzle. My point is that the three premises cannot be jointly justifiably believed, and that that is a minimum requisite for the puzzle to be compelling. If I am correct, thus, we need not embrace philosophical skepticism just in order to solve the puzzle. In section ( $(3)$, I will argue that, even ignoring the general problems raised in section $\$ 2$, the arguments provided by Goldberg in support of (2) are not compelling: once we take into account the possibility of different epistemic perspectives, those arguments lose their original appeal. 


\section{JUSTIFICATION, RELIABILITY AND TRUTH}

If (2) is true, philosophers don't have at their disposal a reliable method for forming philosophical beliefs regarding contested matters. So, if reliability is thought of as a necessary condition for justification(1)-, philosophical theses about contested matters are not justified-(3) is false-. But that is a very pessimistic conclusion, one that we would like to avoid if possible. Moreover, intuitively, we would say that at least some philosophers have epistemic justification for at least some of their philosophical beliefs (even on contested matters).

Now, I think that the first statement of the puzzle is very problematic. In fact, there is no consensus regarding (1). Not every philosopher would agree in that reliability is a necessary condition for epistemic justification. A quick look into the literature shows this point. There are philosophers that reject the idea that reliability is a necessary condition for justification; moreover, there are philosophers that go even further, rejecting the idea that justification is truth-aimed. Here is just an example from Cruz\&Pollock:

\footnotetext{
We conclude from this that a truth-aimed externalist epistemology is not entitled to carry the day solely on the allegation that it is intrinsic to beliefs or the processes of belief formation that they must aim at truth. Instead, the right picture in our view involves truth being a person's aim (at least some of the time), while beliefs are formed through epistemic norms that only answer to themselves as evaluative standards.(Cruz\&Pollock 2004, pp. 24)
}

It should be clear that it is a contested matter whether reliability is a necessary condition for epistemic justification. If that is so, the first horn of the puzzle loses it's primary appeal. But the problem I want to point out is not just that many philosophers actually reject (1). The problem is that, as long as it is a contested matter in philosophy whether reliability is a necessary condition for epistemic justification (and a quick look into the literature shows that it is) it can be said, if one takes point (2) seriously, that it was not reliably formed, and thus, 
that one is not epistemically justified in affirming it. The point is this: assuming I justifiably believe (2), then I have reasons to believe that I do not have a reliable method of forming beliefs about contested matters in philosophy. But I am a philosopher and the question of whether reliability is a necessary condition for epistemic justification is a contested matter in philosophy. Thus, if I am justified in in believing (2), I am not justified in believing (1). Of course, the point applies to any philosopher: if one is justified in believing (2), one cannot be justified in believing (1), as long as it is a contested philosophical matter.

It could be said that this is no surprise. It is precisely Goldberg's aim to emphasize that there are three claims that are independently plausible but that cannot be simultaneously true. Thus, what I just said in the previous paragraph would only prove that Goldberg was right. I don't think that that is the case. First of all, one could run the same argument above in order to prove that (2) alone cannot be rationally believed: if Goldberg's arguments regarding (2) are successful, then (2) itself could be deemed as unreliably formed, for it is plausible to say that (2) is a contested philosophical thesis -In fact, I believe Goldberg's arguments supporting (2) are not compelling, as I'll argue in the next section (\$3). Thus, given that it is a contested philosophical matter itself , (2) is a self undermining premise (at least for any philosopher). Thus, there is no way in which a philosopher could be justified in believing (2), as long as it is a contested philosophical matter. That's enough to disentangle Goldberg's puzzle, for it seems that (2) is not defensible even independently assessed. But let me ignore that problem for the moment. Note that what I am saying is not trivially entailed by Goldberg's claim that (1), (2) and (3) cannot be simultaneously true. My point was not that (1) and (2) cannot be simultaneously true, for they actually can. What I am arguing is that they cannot be jointly rationally believed. The general point I want to make is that although Goldberg's puzzle says that (1), (2) and (3) cannot be simultaneously true, it is 
needed, in order for the puzzle to be compelling, or to have any interest for philosophers, that they could at least be jointly rationally believed by a philosopher. If one takes (2) seriously (and given that (1) is a philosophical contested matter), one has at least to suspend judgment about (1), for (2) provides evidence that (1) was not reliably formed. Thus, although one could continue believing (1), wouldn't be justified in doing so. Thus, even if (1) and (2) were true, one could never be justified in believing both of them. My point could therefore be stated as follows: (2) constitutes an Undercutting Defeater for (1), (3) and for itself - it provides evidence that undermines the evidential connection between the rest of the evidence and the other premises. Thus, there is no way of justifiably believing (2), or the combination of (2) with either (1), (3) or both.

There is a final worry concerning the puzzle. Justification and reliability are philosophical notions (they were created by philosophers).Thus, asking whether philosophy possesses a reliable method or produces justified claims, is equivalent to asking philosophy to assess itself from an epistemic point of view. The question consists, thus, in whether philosophy can meet their own epistemic standards or not. And that leads to a very strange situation: on the one hand, if philosophy cannot meet those standards, it means that it is epistemically flawed. But in that case is not even clear the standards themselves were legitimate in the first place (for they were formulated within a discipline under epistemic suspicion, so to say). So, we cannot learn any lesson from this first situation. On the other hand, if philosophy actually meets its own epistemic standards, the situation is not very illuminating either. We cannot conclude, for example, that philosophers' theses are epistemically well supported, for supposing that would amount to presuppose already that the self-imposed requisites were legitimate, that is, that the notions of justification and reliability are not epistemically flawed. The general point is that there seems to be something problematic with asking a method (in this case a 
philosophical method) to assess its own epistemic credentials. Therefore, philosophy is not worse in that respect than other disciplines of which we do not hold a skeptic attitude.

The previous arguments show that it's not at all clear that Goldberg's puzzle is a legitimate one. In the next section I'll argue that even ignoring those problems, Goldberg's arguments supporting (2) can be undermined once the importance of the philosopher's epistemic perspective is taken into account.

\section{PHILOSOPHICAL DIVERSITY}

In this section I'll examine some arguments in support of point (2). I will claim that once the philosopher's epistemic perspective is taken into account, those arguments lose their initial appeal. My main point is that, as long as it is possible to tell a different story about philosophical diversity, the thesis of philosophers' unreliability is not forced upon us.

I will assess three arguments in favor of the unreliability of philosophical methods on contested matters: The unreliable method argument, The dangerous context argument and The undercutting defeater argument. Let me begin with The unreliable method argument. This argument goes as follows: imagine a contested matter in which the parties use the same method. In that case, the fact of diversity of opinions undermines the idea that the method in question is a reliable one, for it cannot be the case that it produces a preponderance of true beliefs. If the method is shared and, as used by different people, it produces incompatible beliefs, it cannot be a reliable one.

The first thing to notice is that even if the argument were correct, it wouldn't be so bad. First of all, it only covers cases of philosophical disagreement where the belief-forming method is shared. Nevertheless, it is plausible to think that a lot of philosophical disagreements (maybe the most interesting and persistent ones) emerge because of the diversity of philosophical methods. Secondly, the 
argument only shows that a method is unreliable regarding some topic (the topic applied to which it produces a diversity of opinion), but it does not show that it's not reliable regarding all the other philosophical topics where its application doesn't produce a diversity of opinion. Thirdly, it only covers disagreements where the diversity of opinion is not due to an error on the part of one of the philosophers involved (that is, cases in which the method is reliable but one of the parties applied it incorrectly). Thus, even granting that the argument is sound, the scope of its conclusion is rather limited: philosophers' disagreement, as long as they share the method and it is not the case that the disagreement is due to a performance error on the part of one of them, shows that the method they are using is not reliable regarding the topic under discussion. To be sure, that is not a terrible consequence unless it is shown that the described situation is sufficiently common within philosophy. I don't think it is. In any case, the burden of proof is here on my opponent's side.

That being said, the argument has a problem that is pointed out by Goldberg himself: it assumes that there are specifically philosophical methods. For someone not willing to accept that, the argument has no dialectical force. Goldberg is aware of that, and presents a different kind of argument that doesn't need to assume specifically philosophical methods: The dangerous context argument. The dangerous context argument presuppose that the methods used by philosophers within philosophical contexts are the same they use in other contexts. But even if those methods are generally reliable, philosophical diversity creates a dangerous context, analogous to a context of poor lightening with respect to vision. Dangerous contexts turn otherwise reliable methods into unreliable ones. It is important to note though (and Goldberg himself is aware of this), that insofar as it is possible to explain diversity of opinions in a different way, The dangerous context argument is not forced upon us.

Manuscrito - Rev. Int. Fil., Campinas, v. 36, n. 2, p. 215-228, jul.-dez. 2013. 
Now, I believe that such explanation can be provided. I have defended elsewhere (Lo Guercio 2012) that we must distinguish two different kinds of philosophical disagreements, depending on to what extent the epistemic perspective of the parties is shared. In that article, I labeled Weak Disagreements those where the epistemic perspective is widely shared, and Strong Disagreements those where the parties' epistemic perspectives relevantly differ. An epistemic perspective includes a conception of what facts count as evidence, the relative weight assigned to different kinds of evidence and what epistemic goals are more relevant, i.e. a number of normative and methodological commitments. Different epistemic perspectives may determine differences with respect to all those issues. The insight behind these definitions is that usual accounts of disagreement fail to acknowledge a very important feature of the notion of evidence: being evidence is not a straightforwardly factual property, but a property that a proposition has only relative to some system of epistemic norms, policies, goals, and methodological commitments. That is, 'evidence' is an implicitly relative notion: what things count as evidence and to which extent they support some belief (or degree of confidence in some belief) depends, at least in part, on an epistemic perspective. Back then, I argued that philosophers frequently disagree about their epistemic perspectives (sometimes, the disagreement is implicit); that is, about the facts they consider evidence, the relative weight and relevance of that evidence, and the epistemic goals that are priority (apart from truth: empirical adequacy, coherence, explanatory power, among others). Examples of this are the discussions about the evidential role of intuitions, the role of semantic competence in philosophical research, the weight assigned to thought experiments, etc. All philosophers take implicit or explicit commitments regarding what I've called an epistemic perspective. The difference between epistemic perspectives, together with the idea that numerous philosophical disagreements between parties with a shared 
epistemic perspective might be due to performance errors, can explain to a great extent the fact of the diversity of philosophical opinions.

Now, how this fact bears on the discussion about the reliability of philosophical methods? Well, as Goldberg himself claims, as long as the diversity of opinion can be explained appealing to differences in epistemic perspective, there is no need to conclude that philosophy is a "dangerous context", similar to poor lightening in the case of vision. Different perspectives determine different access to the relevant evidence in the sense that include some commitments (implicit or explicit) regarding what facts count as evidence and what evidence is more relevant. If that's right, we need not jump from the fact of diversity to the conclusion that philosophers form their beliefs regarding contested matters through unreliable methods.

What about The undercutting defeater argument? This argument states that the fact of diversity of opinions regarding some philosophical issue constitutes an undercutting defeater for my own belief. Even if it is granted that I used a reliable method, the evidence provided by diversity diminishes the subjective probability that my belief is true. So, even if I relied on a reliable method, I'm not justified, for I have reasons to believe that the method was not reliable. The conclusion is that, regarding contested matters in philosophy, philosophers are not justified, even if they formed their beliefs through a reliable method.

Now, an undercutting defeater is evidence that undermines the evidential connection between some other piece of evidence and the relevant belief. But diversity can only constitute an undercutting defeater if the other shares to some relevant extent my epistemic perspective, that is, The undercutting defeater argument only works for cases of weak peer disagreement. If my rival shares my epistemic perspective, I'm sure he has a method at least as reliable as mine. Thus, diversity of opinions serves as an undercutting defeater. But if my opponent has a rather different epistemic perspective, the disagreement might be 
explain just by that fact. Therefore, I have no reason to take the disagreement as an indicator that my belief might be false. I believe, though, that the most relevant, interesting and persistent discussions among philosophers are cases of strong disagreement, that is, disagreement between philosophers with different methodological conceptions, different ideas about what facts constitutes philosophical evidence or what epistemic goals are relevant, etc. Thus, as long as the scope of the argument only reaches cases of weak disagreement, the situation is not so bad after all. Or, in any case, an argument is needed (or several examples) that most persistent philosophical disagreements are carried between philosophers (or group of philosophers) deploying relevantly similar philosophical perspectives.

\section{CONCLUSION}

In this paper I attempted to resolve a puzzle that challenges us all as philosophers. I argued that the puzzle's legitimacy is dubious for several reasons. First of all, it is not only the case that their premises cannot be simultaneously true, but they cannot be jointly rationally believed by a philosopher. If this is correct, the problem loses its primary appeal: if the puzzle is to be a serious problem, it should be possible at least to rationally believe their premises. The second reason to doubt the legitimacy of the puzzle has to do with the known problems that emerge from asking a method to asses its own epistemic credentials. It is not clear that a method, in order to be justified or to produce justified beliefs, should be able to assess itself positively from an epistemic point of view; or, in any case, the problem is not specific of philosophy.

On the other hand, I argued that even ignoring the issues above mentioned, one can deny that there is a real problem, on the grounds that premise (2) has not been properly argued for. I assessed the three arguments provided by Goldberg in favor of (2) and showed them wanting: concerning both The unreliable method argument and The Manuscrito - Rev. Int. Fil., Campinas, v. 36, n. 2, p. 215-228, jul.-dez. 2013. 
undercutting defeater argument, I pointed out the limited scope of their conclusion, which makes them innocuous. As to the The dangerous context argument, I showed that a different story regarding philosophical diversity could be provided, making the argument lose its primary appeal.

\section{REFERENCES}

CRUZ, J., POLLOCK, J. "The Chimerical Appeal of Epistemic Externalism”. In R. Schantz (ed.) (2004), pp. 125-143.

DAVID, M. “Truth as the Epistemic Goal”. In M. Steup (ed.) (2001), pp. 151-170.

FOLEY, R. The Theory of Epistemic Rationality. Cambridge, Mass.:Harvard University Press, 1987.

GOLDBERG, S. "Reliabilism in philosophy". Philosophical Studies, 142, (1), pp. 105-117, 2009.

KVANVIG, J. "Truth is not the primary epistemic goal". In Steup, M. and Sosa, E. (eds.) (2005), pp. 285-96.

LO GUERCIO, NICOLÁS. "Philosophical Peer Disagreement", Logos\& Episteme, 3, (3), pp. 459-467, 2012.

MAITZEN, S. "Our Errant Epistemic Aim”. Philosophy and Phenomenological Research, 55, (4), pp. 869-876, 1995.

LEWIS, D. "Immodest Inductive Methods". Philosophy of Science, 38, (1), pp. 54-63, 1971.

SCHANTZ, R. The Externalist Challenge. Berlin: De Gruyter, 2004.

STEUP, M., SOSA, E. Contemporary Debates in Epistemology. Oxford: Blackwell Publishing, 2005.

STEUP, M. Knowledge, Truth, and Duty. New York: Oxford University Press, 2001. 